\title{
Calibration of the passive cavity aerosol spectrometer probe for airborne determination of the size distribution
}

\author{
Y. Cai, J. R. Snider, and P. Wechsler \\ University of Wyoming, Department of Atmospheric Science, Laramie, WY 82071, USA \\ Correspondence to: J. R. Snider (jsnider@uwyo.edu) \\ Received: 4 April 2013 - Published in Atmos. Meas. Tech. Discuss.: 2 May 2013 \\ Revised: 26 July 2013 - Accepted: 1 August 2013 - Published: 11 September 2013
}

\begin{abstract}
This work describes calibration methods for the particle sizing and particle concentration systems of the passive cavity aerosol spectrometer probe (PCASP). Laboratory calibrations conducted over six years, in support of the deployment of a PCASP on a cloud physics research aircraft, are analyzed. Instead of using the many calibration sizes recommended by the PCASP manufacturer, a relationship between particle diameter and scattered light intensity is established using three sizes of mobility-selected polystyrene latex particles, one for each amplifier gain stage. In addition, studies of two factors influencing the PCASP's determination of the particle size distribution - amplifier baseline and particle shape - are conducted. It is shown that the PCASP-derived size distribution is sensitive to adjustments of the sizing system's baseline voltage, and that for aggregates of spheres, a PCASP-derived particle size and a sphere-equivalent particle size agree within uncertainty dictated by the PCASP's sizing resolution. Robust determinations of aerosol concentration, and size distribution, also require calibration of the PCASP's aerosol flowrate sensor. Sensor calibrations, calibration drift, and the sensor's non-linear response are documented.
\end{abstract}

\section{Introduction}

Aerosol size distribution measurements are an essential part of climate (Charlson et al., 1992), visual haze (Kleinman et al., 2007) and cloud physics studies (Kleinman et al., 2012). The passive cavity aerosol spectrometer probe (PCASP) is a convenient and reliable instrument for making airborne measurements of the size distribution over a broad range of particle size (Strapp et al., 1992). Employing a He-Ne laser $(\lambda=0.633 \mu \mathrm{m})$, the PCASP measures the scattering intensity produced by single particles, and classifies the intensity values into a histogram that constitutes the basis for the determination of the size distribution. Scattering theory (Twomey, 1977; pp. 199-217), with an assumed particle refractive index, are used to convert from intensity to particle diameter (assuming spherical particle shape). Three amplifier gain stages are used to span the range of particle diameters the probe is sensitive to $(0.1 \mu \mathrm{m} \leq D \leq 3.0 \mu \mathrm{m})$.

This paper describes calibration methods developed for the particle sizing and particle concentration systems of the PCASP. We deviate from the recommendations of the manufacturer (Particle Measuring Systems, 2002). What we present is a simpler approach, and in the case of the flow calibration, an approach that accounts for non-linearity in the response characteristics of the probe's flowrate sensor. Over the past six years we have applied these calibrations to three PCASPs. Two of these - PCASP-1 (SN=10130502-29) and PCASP-2 (SN=39798-0200-26) - are operated on the University of Wyoming King Air. The King Air is one of the aircraft allocated as part of the National Science Foundation's Lower Atmospheric Observing Facility (Wang et al., 2012). A PCASP owned by the National Center for Atmospheric Research (NCAR) was also calibrated ( $\mathrm{SN}=23738-0491-08)$. That work was conducted in support of two research projects involving the NCAR C-130 (Snider et al., 2013). The focus of this paper is the calibration of the PCASP-1 and PCASP-2. Those PCASPs, and the NCAR PCASP, have the SPP-200 electronics package, developed by Droplet Measurement Technologies (DMT), and each is installed in an external pod during airborne operations. 


\section{Methods}

\subsection{Data acquisition}

The measurements we report were conducted in our laboratory at the University of Wyoming. Data signals from a PCASP, and a condensation particle counter (CPC; TSI, 2000c), were recorded using a custom-built data acquisition system. The data system ingests signal data once per second (1 Hz sampling). Recorded PCASP data include the particle count histogram and output from the probe's flowrate sensor. A size distribution was also obtained using a TSI Model 3936 Scanning Mobility Particle Sizer (SMPS; TSI, 2000a, 2001). The SMPS size distribution was derived using the Aerosol Instrument Manager (TSI, 2001) software and was recorded as a $300 \mathrm{~s}$ average.

\subsection{Particle generation}

Two test particle generators were used in this investigation. The first is the Model PG-100 developed by Particle Measuring Systems (Particle Measuring Systems, 1992). This generator produces liquid droplets by atomizing a hydrosol containing monodisperse polystyrene latex (PSL) spheres (Duke Scientific Corporation). The droplets are mixed with dry air, to evaporate their water fraction, and the resulting dried PSL particle stream is then routed into the inlet needle of the PCASP (Sect. 3.1). No attempt was made to remove particles containing more than one PSL sphere (aggregates). As we will see, particles smaller than the PSL diameter are also produced by the PG-100. This occurs when droplets containing the hydrosol's solute component, but no PSL sphere, are atomized (Kinney et al., 1991). During field deployment of the King Air, we use the PG-100 to conduct ground checks of the PCASP's particle sizing system. In Sect. 3.6 we analyze particle size distributions produced by the PG- 100 generator and contrast them with distributions produced by our other particle generator.

The other particle generation system also creates droplets by atomizing PSL hydrosols. In this system we use an electrostatic classifier (EC), operated downstream of a dryer and charge neutralizer, to select a mobility-classified subset of the generated particles. The system consists of a TSI Model 3076 atomizer, a TSI Model 3062 diffusion dryer, a ${ }^{210} \mathrm{Po}$ charge neutralizer (Covert et al., 1997), a TSI DMA3081 electrostatic classifier (TSI, 2000a), and a home-built aerosol diluter. An impactor is operated on the inlet side of the EC. Assuming a particle density $1050 \mathrm{~kg} \mathrm{~m}^{-3}$, the particle diameter corresponding to $50 \%$ impaction is $1.4 \mu \mathrm{m}$.

These preparatory steps isolated aerosol particles at the PSL diameter reported by Duke Scientific, but, as we shall see, the resulting size distribution also had a small contribution from particles larger than the PSL spheres. These particles were produced when a relatively large solution droplet, containing a greater than average amount of solute, and one
PSL sphere, was atomized, dried, and charged with two elementary charges. We refer to these particles as charge doublets. Within the EC, these particles have the same electrical mobility as a singly charged PSL sphere. When detected by the SMPS (Sect. 2.1), subsequent to recharging, the particles initially classified as a charge doublet are predicted to appear at $0.19 \mu \mathrm{m}$ (PSL diameter $0.125 \mu \mathrm{m}$ ), at $0.31 \mu \mathrm{m}$ (PSL diameter $0.199 \mu \mathrm{m}$ ) and at $0.85 \mu \mathrm{m}$ (PSL diameter $0.491 \mu \mathrm{m}$ ).

Throughout this document we present the PSL diameter with three-digit precision, not to imply that the value is known with that degree of certainty, but to distinguish the PSL diameter from particle size determinations made using the PCASP and SMPS. The latter are presented with twodigit precision, consistent with the fact that the relative precision of a particle size determination is controlled by the instrument-dependent size resolution. For a $0.2 \mu \mathrm{m}$ particle the relative size resolution is $4 \%$ and $10 \%$ for the SMPS and PCASP, respectively. Typically, drift of the PCASP and SMPS sizing calibrations is about a factor of two smaller than these resolution-limited uncertainties (Kinney et al., 1991; Rosenberg et al., 2012).

\subsection{PSL hydrosols}

Diluted PSL hydrosols were used in this work. These were prepared by diluting between 2 and 20 drops of the stock PSL suspension (Duke Scientific) in $50 \mathrm{~mL}$ of filtereddeionized water. Aerosols used in the sizing calibration, and in the validation of the flowrate calibration, were prepared by atomizing the diluted PSL hydrosols. The concentration of the PSL aerosol particles was varied between 30 and $500 \mathrm{~cm}^{-3}$, depending on the degree of PSL hydrosol dilution and the amount of dilution air that was mixed with the mono-mobility stream exiting the EC. A concentrated PSL hydrosol was also used. This was prepared by diluting 10 drops of stock PSL suspension in $3 \mathrm{~mL}$ of filtereddeionized water. Sphere aggregates were electrostatically selected from the polydisperse aerosol prepared using the concentrated hydrosol. Using theory developed in Hinds (1999, their Sect. 21.2), and specification of atomizer's droplet size distribution (TSI, 2000b), we estimate that at least $90 \%$ of the selected particles were the aggregates we intended to sample. Properties of these double and triple aggregates were evaluated using the SMPS and the PCASP-1. We analyze our measurements of the aggregates in Sect. 3.7.

\section{Results}

\subsection{PCASP sheath and aerosol flow systems}

The generated test aerosols are transmitted to the PCASP's scattering volume via an inlet needle (ID $=500 \mu \mathrm{m})$. At the needle exit, immediately upstream of the laser beam, the stream is combined with sheath air. Because of constriction by the sheath air flow, the diameter of the particle stream, 


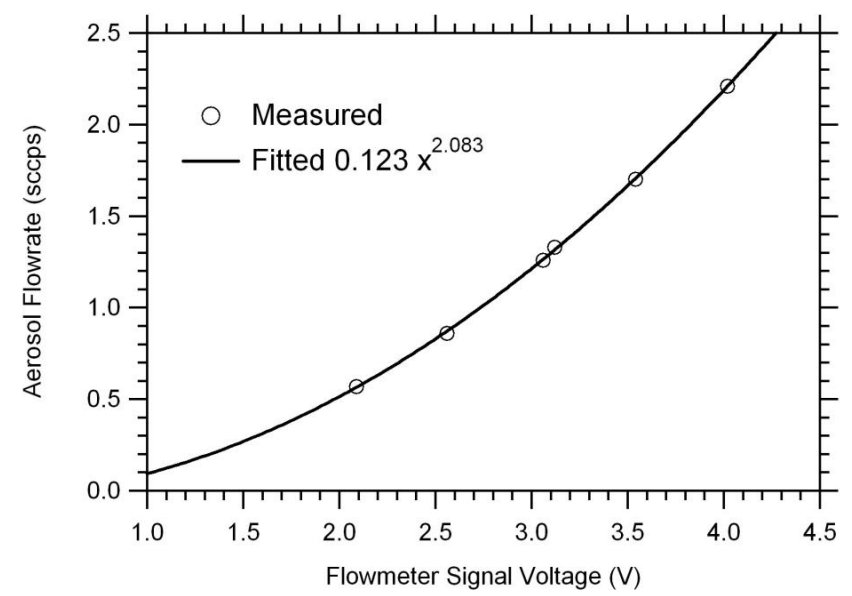

Fig. 1. PCASP-1 aerosol flow calibration curve. The indicated power-law function $\left(\dot{V}=a \cdot V_{\text {out }}^{\mathrm{b}}\right)$ is used to derive the standard cubic centimeter per second (sccps) flowrate, $\dot{V}$, from measurements of $V_{\text {out }}$.

at the point where it crosses the laser, is substantially narrower than the width of the laser beam (Particle Measuring Systems, 2002).

The PCASP manual (Particle Measuring Systems, 2002) advises that the sheath air and aerosol flowrates be set at 15 and 1 standard cubic centimeter per second (sccps), respectively. Within the PCASP, these flows are measured by two electronic mass flow sensors - the Model AWM3300V (Honeywell), for the sheath stream, and the Model AWM3100V (Honeywell), for the aerosol stream. The flowrate signal is converted to flowrate via the calibration described in the next section.

\subsection{Flowrate calibration}

Here our focus is on determination of the PCASP's aerosol flowrate calibration. This is crucial because PCASP concentrations are derived as the ratio of particle count rate (count of particles per $1 \mathrm{~Hz}$ sample) and aerosol flowrate $(\dot{V})$, and because the latter varies with aircraft altitude and airspeed. Using $1 \mathrm{~Hz}$ samples of the flowrate signal, and the calibration, we calculate $\dot{V}$, expressed as a standard cubic centimeter per second (sccps), and also calculate the actual cubic centimeter per second (accps) equivalent of $\dot{V}$. The latter step uses measurements of ambient pressure and temperature and the ideal gas equation.

Flowrate calibrations were conducted using a Gilibrator-2 bubble flow meter (Gilian Instrument Corp.) connected to the inlet side of the PCASP needle. Bubble meter measurements of flowrate (accps), measurements of temperature and pressure, and the ideal gas law were used to evaluate the standardtemperature-pressure representation of the flowrate. Figure 1 shows a flow calibration for PCASP-1. Six calibration points are evident over the range of flowrates encountered during research flights. The indicated power-law function is a con- venient way to describe the non-linear relationship between flow sensor signal voltage and aerosol flowrate.

After establishing the flowrate calibration, we tested to verify that the PCASP reports a very small concentration $\left(<5 \mathrm{~cm}^{-3}\right)$ while sampling filtered air. Also, we conducted tests with the PCASP operating in parallel with the CPC while both were sampling electrostatically classified PSL spheres. Results from one test are illustrated in Fig. 2a and b. Here the "plateaus" correspond to electrostatically classified PSL spheres, and the "valleys" to periods when we were switching the PSL hydrosol. We note that there is good agreement between the CPC- and PCASP-derived concentrations, over a range extending from 40 to $460 \mathrm{~cm}^{-3}$, and that the concentration variability is larger for the PCASP. We also note that these tests evaluated four samples of mobilityselected PSL particles and that concentration varied inversely with particle size.

We find that the concentration variability, expressed as a standard deviation, is four times larger for the PCASP compared to the CPC (Fig. 2b). Moreover, we note that the concentration variability is consistent with the instrument-dependent flowrates and Poisson counting error. This assertion is substantiated in Appendix A.

Table 1 summarizes aerosol flowrate calibrations we obtained for several King Air projects, for both PCASP-1 and PCASP-2. The sixth column has the flowrates for different calibrations evaluated at a fixed flow sensor signal voltage $(2.7 \mathrm{~V})$. Relative to measurements made in 2006 (PCASP-1) and in 2010 (PCASP-2), the maximum shifts of the calibrations are 6 and $17 \%$, respectively.

\subsection{PCASP sizing system}

The PCASP manual (Particle Measuring Systems, 2002) describes the calibration of the probes's particle sizing system. Twelve PSL sizes are specified for calibrating the range of detectable particle diameter (nominally $0.1 \mu \mathrm{m} \leq D \leq 3.0 \mu \mathrm{m}$ ). The manufacturer's methodology leads to a relationship between scattered light intensity and particle diameter. We refer to this relationship as the threshold-diameter table. The table can also be developed with knowledge of the particle's index of refraction and properties of the probe (i.e., laser illumination, scattering geometry and photodetector signal amplification). Our PCASP-1, purchased in 2002, came with a computer code that derives the threshold-diameter table based on the abovementioned particle and probe characteristics (setSPP.exe). By either approach, each of the thirty channels of the PCASP is identified with both an upper-limit sphere diameter and an upper-limit threshold. In the following section, we start with the manufacturer's threshold-diameter table and shift the diameters so that they are consistent with our experimental determinations of the channel that mobility-selected PSL spheres classify into. Because the threshold-diameter table is divided into three gain stages, our sizing calibration involves 
(a)

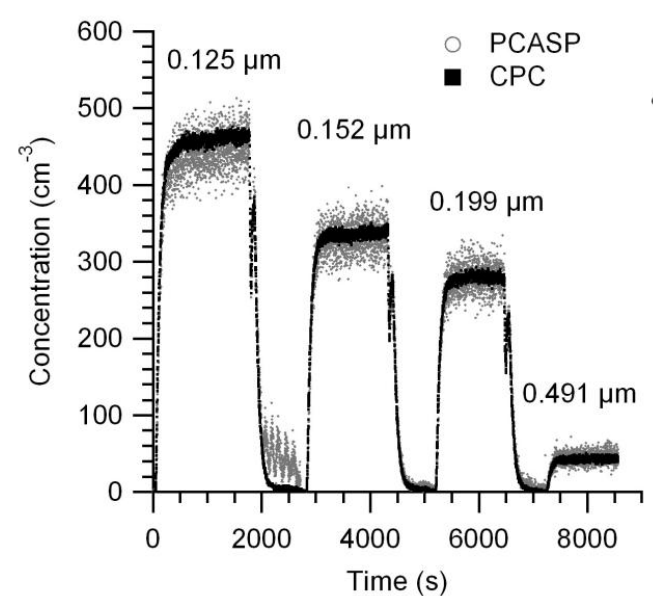

(b)

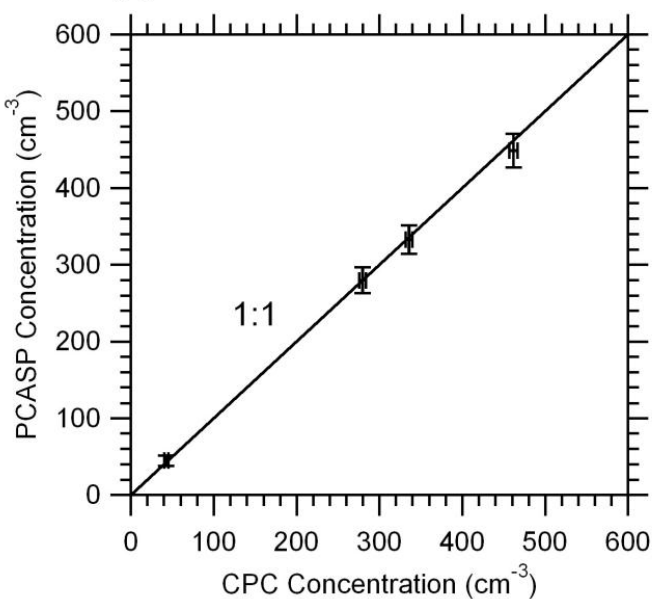

Fig. 2. PCASP-1 and CPC concentration measurements after determination of PCASP-1's aerosol flowrate calibration. (a) Time series of $1 \mathrm{~Hz}$ samples during laboratory measurement of four mobility-selected PSL particles. (b) Time-averaged concentrations, plus and minus one standard deviation for the $700 \mathrm{~s}$ analysis intervals centered at 1400, 3800, 6100 and $8000 \mathrm{~s}$.

Table 1. Summary of calibrations for aircraft field projects.

\begin{tabular}{|c|c|c|c|c|c|c|c|c|}
\hline \multirow{2}{*}{ Project } & \multirow{2}{*}{ Year } & \multirow{2}{*}{ PCASP } & \multicolumn{2}{|c|}{$\begin{array}{c}\text { Aerosol flowrate } \\
\text { calibration coefficients }\end{array}$} & \multirow{2}{*}{$\begin{array}{c}\text { Aerosol flowrate } \\
\text { at } V_{\text {out }}=2.7 \mathrm{~V}, \\
\text { sccps }\end{array}$} & \multicolumn{3}{|c|}{ Diameter Shift, $\mu \mathrm{m}$} \\
\hline & & & $a$ & $b$ & & High gain & Mid gain & Low gain \\
\hline DMIMS & 2006 & 1 & 0.120 & 2.137 & 1.00 & 0.02 & 0.01 & 0.04 \\
\hline CUPIDO & 2006 & 1 & 0.125 & 2.066 & 0.97 & 0.02 & -0.01 & 0.04 \\
\hline CLDGPS & 2008 & 1 & 0.123 & 2.083 & 0.97 & 0.02 & -0.01 & 0.04 \\
\hline KAPEE & 2010 & 1 & 0.129 & 2.046 & 0.98 & 0.02 & 0.01 & 0.04 \\
\hline Current & 2012 & 1 & 0.118 & 2.210 & 1.06 & 0.00 & -0.01 & -0.06 \\
\hline KAPEE & 2010 & 2 & 0.178 & 1.811 & 1.08 & 0.00 & -0.01 & 0.04 \\
\hline LPVEX & 2010 & 2 & 0.156 & 1.936 & 1.07 & 0.00 & -0.01 & 0.04 \\
\hline DOMEX & 2011 & 2 & 0.163 & 1.999 & 1.19 & 0.00 & -0.01 & 0.04 \\
\hline ASCII & 2012 & 2 & 0.166 & 2.040 & 1.26 & 0.00 & -0.01 & 0.14 \\
\hline Current & 2012 & 2 & 0.170 & 1.984 & 1.22 & 0.00 & -0.01 & 0.14 \\
\hline
\end{tabular}

the determination of a diameter shift for each gain stage and an adjustment of the manufacturer's threshold-diameter table. What results is a modified sizing calibration; we refer to this as the calibrated threshold-diameter table.

\subsection{Sizing calibration}

For these investigations we use the particle generation system with the electrostatic classifier (Sect. 2.1) and generate a steady stream of mobility-selected PSL particles. The test particle concentration was stable for the duration of each of the testing intervals $(300 \mathrm{~s})$. With the PCASP sampling at approximately 1 accps, the number of particles counted in $300 \mathrm{~s}$ was between $10^{4}$ and $10^{5}$. Starting with the PCASP's test-averaged count histogram, we determine the channel corresponding to the most counting events.
Results for PCASP-1 are presented in Fig. 3. This graphic is split to show findings for the high-gain (Fig. 3a), mid-gain (Fig. 3b), and low-gain amplifier stages (Fig. 3c). The filled black circles in Fig. 3a-c are plotted at the midpoint of the channel with the largest number of counts, the dotted black line illustrates the manufacturer's threshold-diameter table, and the dotted red vertical and horizontal lines indicate the calibrated threshold-diameter table.

For the mid-gain and low-gain channels (Fig. $3 b$ and c), we find that the manufacturer's calibration (dotted black line) does not precisely define the PSL diameter. For these two channels the experimentally-derived diameter shifts are $\Delta D=-0.01 \mu \mathrm{m}$ (mid gain) and $\Delta D=-0.06 \mu \mathrm{m}$ (low gain). Our most recent determination of the calibrated thresholddiameter table for PCASP-1 is provided in Table 2.

Results presented in the final column of Table 2 demonstrate that this PCASP-1 calibration has a positive increment 

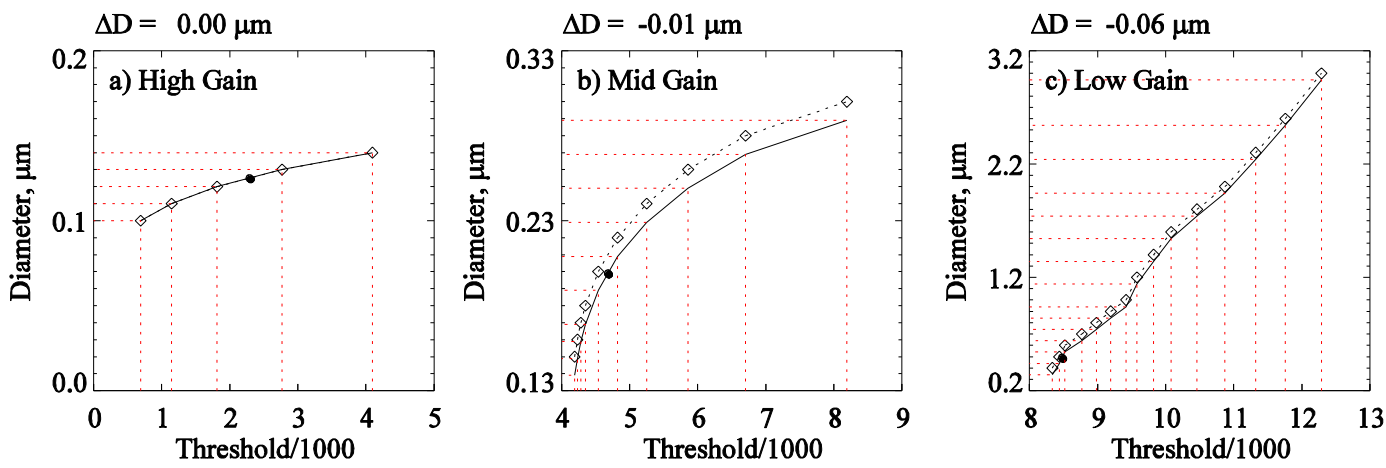

Fig. 3. The manufacturer threshold-diameter table (dotted black line connecting diamonds), experimental determination of the channel that PSL spheres $(0.125,0.199$, and $0.491 \mu \mathrm{m})$ classify into (filled black circle), and the calibrated threshold-diameter table (dotted red vertical and horizontal lines). The thirty thresholds are internal electronic representations of the channel boundaries.

Table 2. Threshold, manufacturer diameter and calibrated diameter for PCASP-1.

\begin{tabular}{|c|c|c|c|c|}
\hline $\begin{array}{l}\text { Channel } \\
\text { number }\end{array}$ & $\begin{array}{l}\text { Gain } \\
\text { Stage }\end{array}$ & threshold $^{\mathrm{a}}$ & $\begin{array}{l}\text { Manufacturer's } \\
\text { diameter, } \mu \mathrm{m}\end{array}$ & $\begin{array}{c}\text { Calibrated } \\
\text { diameter, } \mu \mathrm{m}\end{array}$ \\
\hline 0 & high & 692 & 0.10 & 0.10 \\
\hline 1 & high & 1146 & 0.11 & 0.11 \\
\hline 2 & high & 1814 & 0.12 & 0.12 \\
\hline 3 & high & 2769 & 0.13 & 0.13 \\
\hline 4 & high & 4096 & 0.14 & 0.14 \\
\hline 5 & mid & 4192 & 0.15 & $0.14(0.145)^{\mathrm{b}}$ \\
\hline 6 & $\operatorname{mid}$ & 4231 & 0.16 & 0.15 \\
\hline 7 & $\operatorname{mid}$ & 4282 & 0.17 & 0.16 \\
\hline 8 & mid & 4348 & 0.18 & 0.17 \\
\hline 9 & mid & 4537 & 0.20 & 0.19 \\
\hline 10 & mid & 4825 & 0.22 & 0.21 \\
\hline 11 & $\operatorname{mid}$ & 5251 & 0.24 & 0.23 \\
\hline 12 & $\operatorname{mid}$ & 5859 & 0.26 & 0.25 \\
\hline 13 & $\operatorname{mid}$ & 6703 & 0.28 & 0.27 \\
\hline 14 & $\operatorname{mid}$ & 8192 & 0.30 & 0.29 \\
\hline 15 & low & 8335 & 0.40 & 0.34 \\
\hline 16 & low & 8435 & 0.50 & 0.44 \\
\hline 17 & low & 8520 & 0.60 & 0.54 \\
\hline 18 & low & 8768 & 0.70 & 0.64 \\
\hline 19 & low & 8981 & 0.80 & 0.74 \\
\hline 20 & low & 9194 & 0.90 & 0.84 \\
\hline 21 & low & 9418 & 1.00 & 0.94 \\
\hline 22 & low & 9579 & 1.20 & 1.14 \\
\hline 23 & low & 9825 & 1.40 & 1.34 \\
\hline 24 & low & 10080 & 1.60 & 1.54 \\
\hline 25 & low & 10460 & 1.80 & 1.74 \\
\hline 26 & low & 10872 & 2.00 & 1.94 \\
\hline 27 & low & 11322 & 2.30 & 2.24 \\
\hline 28 & low & 11759 & 2.60 & 2.54 \\
\hline 29 & low & 12288 & 3.00 & 2.94 \\
\hline
\end{tabular}

${ }^{a}$ The thirty thresholds are internal electronic representations of the channel boundaries. A digitized pulse height is compared to the thresholds to infer the channel a particle is classified into. ${ }^{\mathrm{b}}$ The recommended diameter. See text for details. from the diameter of the last channel of the mid-gain stage $(0.29 \mu \mathrm{m})$ to the diameter of the first channel of the low-gain stage $(0.34 \mu \mathrm{m})$. A positive increment at this particular gain boundary was the case for all of our calibrations. This can be verified by applying the following example to all other midgain to low-gain transitions. For the most recent PCASP-1 calibration (Table 2), the values $0.29 \mu \mathrm{m}$ and $0.34 \mu \mathrm{m}$ were derived by adding the manufacturer's diameters $(0.30 \mu \mathrm{m}$ and $0.40 \mu \mathrm{m}$; Table 2$)$ to the mid- and low-gain shifts $(-0.01 \mu \mathrm{m}$ and $-0.06 \mu \mathrm{m}$ ) from the fifth row of Table 1.

In contrast to the positive increment at the mid- to low-gain boundary, our calibration produces ambiguity at the high- to mid-gain boundary. This is made evident both in the last column of Table 2 (calibrated diameter), and in Fig. 3a and b. In the table, and in the two figures, the calibrated diameter of the last channel of the high-gain stage and the first channel of the mid-gain stage both indicate $0.14 \mu \mathrm{m}$. At this gain stage boundary, a sizing overlap, or even a sizing reversal, has been documented. In the case of the PCASP-1 in the CUPIDO project the reversal can be verified by adding the manufacturer's diameters at channels \#4 and \#5 (0.14 and $0.15 \mu \mathrm{m}$; Table 2) to the high- and mid-gain shifts (0.02 and $-0.01 \mu \mathrm{m})$ from the second row of Table 1 .

Rosenberg et al. (2012) also reported sizing calibrations for a SPP200-modified PCASP. When doing these calibrations at a particle diameter that was large enough to register in the lowest channel of an adjacent smaller-gain stage, they noted that most of the counting events did not conform to their expectation. They commented that an "undocumented process" was preventing the expected counting into the smaller-gain portion of the histogram. The net result was that the width of the last channel of the larger-gain stage was broadened and that the width of the first channel of the smaller-gain stage was narrowed. We note that this narrowing is consistent with the diameter overlap we document for the high- to mid-gain transition. Rosenberg et al. (2012) proposed two workarounds for the ambiguity associated with narrowing (overlap): (1) merging the two channels (e.g., \#4 
and \#5), to produce a size distribution with one less channel, or (2) setting the upper-limit diameter of the last channel of the larger-gain stage equal to the lower limit of the first channel of the smaller-gain stage.

Researchers at NCAR have implemented a solution to the overlap problem. Their approach is to generate a nonconventional threshold-diameter table with two of the three smallest thresholds removed from the mid-gain stage (4192 and 4282; Table 2), and with two channels added to the low-gain stage to maintain the total number of channels at 30 . For the NCAR SPP200-version PCASP, Snider et al. (2013) did not report a diameter overlap at either the high- to mid-gain stage boundary or at the mid- to low-gain boundary. For data acquired by our PCASP-1, as it is currently configured, we rectify the problem by replacing one of the calibrated diameters with $0.145 \mu \mathrm{m}$ (Table 2). Our ad hoc solution removes the overlap but produces two channels (\#5 and \#6; see Table 2) with diameter widths a factor of two narrower than the manufacturer's calibration.

\subsection{Effect of amplifier baseline reference voltage}

Each of the PCASP's gain stages has a variable resistor that offsets the scattering pulse amplitude relative to an internal reference. Positive offsetting is desired because the conversion from pulse height amplitude (an analog voltage) to a threshold (an integer) necessitates that the former starts at a value in excess of the internal reference (the baseline circuit's analog ground). The baseline is set, by the manufacturer, at slightly above ground, generally less than $0.4 \mathrm{~V}$.

In Fig. 4a-c we present determinations of the ambient particle size distribution made with the PCASP-1 and the SMPS. For these tests the SMPS scan interval is $300 \mathrm{~s}$ (Sect. 2.1). Hence, we present the size distributions as a $300 \mathrm{~s}$ average. Distribution uncertainties, indicated by swaths of black (PCASP) and gray (SMPS), were evaluated as a Poisson counting error (Appendix A). Also in Fig. 4a-c, a vertical dashed line is drawn at the mid-point of the first channel of the mid-gain stage. In Fig. 4b, we note that the PCASP and SMPS distributions are in agreement, within the Poisson counting uncertainties, up to $0.4 \mu \mathrm{m}$ diameter, and that beyond $0.4 \mu \mathrm{m}$ there are too few particles to make a judgment about the PCASP/SMPS comparison.

Because the PCASP channel \#5 has the smallest threshold of the mid-gain stage, particle counts going into that channel are most sensitive to a change of the mid-gain baseline (Particle Measuring Systems, 2002). Also, this sensitivity is compounded by the fact that the slope of the threshold-diameter relationship is large for channels \#5, \#6, \#7, \#8 and \#9, relative to the slope of neighboring channels. Two years prior to the measurements shown in Fig. $4 \mathrm{a}-\mathrm{c}$ we noticed that size distributions reported by the PCASP-1 consistently exhibited a local maximum in channel \#5, but we were uncertain whether this was a real phenomenon or an instrumental bias. Since that time (2010), and with advice from DMT (B. Daw-
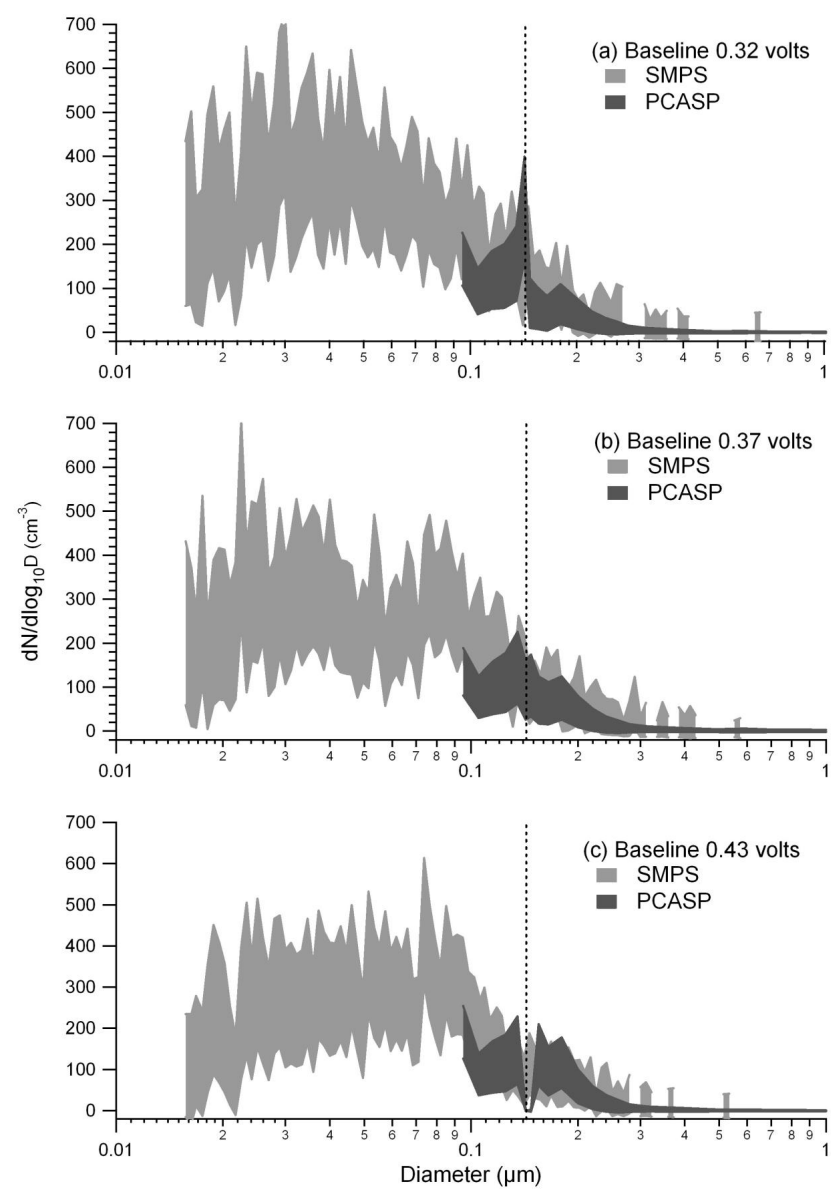

Fig. 4. Comparison of simultaneous laboratory measurements of the ambient particle size distribution using a SMPS and PCASP-1. Comparisons are shown for three different settings of the mid-gain baseline voltage. The vertical dashed lines indicate the center of the first channel of the mid-gain stage. The gray and black areas represent Poisson counting errors. See text for details.

son, personal communication, 2010), we have compared distributions from the PCASP-1 and the SMPS. During these experiments we adjusted the mid-gain baseline and produced a smooth transition across channel \#5. The effect of too small a baseline, or too large, is shown in Fig. 4a and c, respectively. If the baseline is set too small, we see an unrealistic enhancement of detections in channel \#5 (Fig. 4a), and vice versa in Fig. 4c. In addition, in Fig. 4c, we see that particle counts go to zero in channels \#5 and \#6 and are enhanced in channels \#7, \#8 and \#9. These results are consistent with the previously stated information about the mid-gain electronics and sensitivity. The results also underscore the utility of having an independent measure of the size distribution, for comparing to the PCASP, and the utility of the Poisson estimate of the particle counting error (Appendix A). 

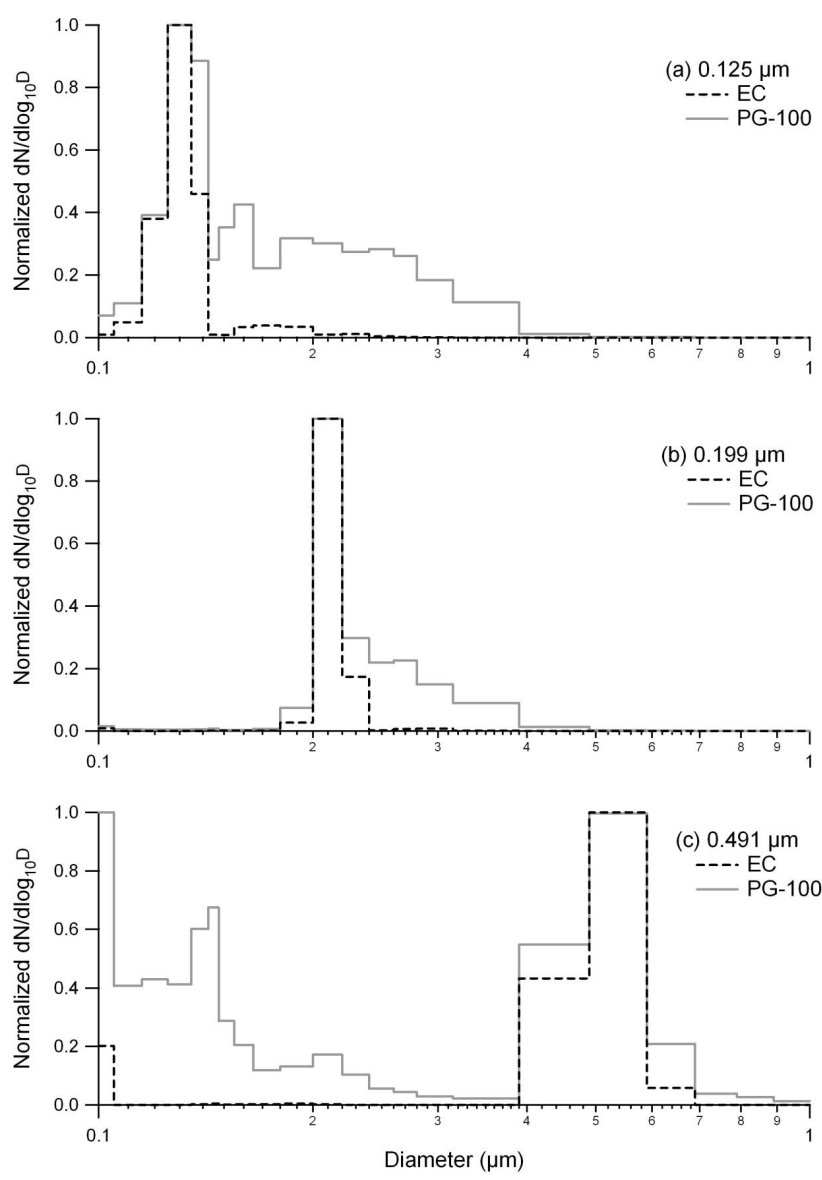

Fig. 5. Normalized size distributions produced by atomizing hydrosols containing $0.125,0.199$, and $0.491 \mu \mathrm{m}$ PSL spheres. Results for both particle generators are presented.

\subsection{Size distributions produced by the PG-100}

As we discussed in Sect. 2.2, testing of the PCASP's sizing system is different when we operate the probe in the field. In that situation an aerosol generator (PG-100) is used to produce particles via PSL hydrosol atomization. After drying, the generated particles are sampled by the PCASP without size selection.

Figure 5 compares PCASP determinations of the size distribution for aerosols generated by atomization (PG-100) and by atomization followed by electrostatic classification (EC). Because the measurements were made at different times, the distributions are normalized.

For the 0.125 and $0.199 \mu \mathrm{m}$ aerosols coming from the PG100 , particles substantially larger than the PSL size were detected. These particles are PSL spheres mixed with solute (Sect. 2.2), with an additional PSL sphere, or with a combination of solute and an additional PSL sphere. Consequently, the 0.125 and $0.199 \mu \mathrm{m}$ PG-100 size distributions are broadened, mostly toward larger size, relative to the distribution obtained with the electrostatic classifier. In spite of the broad- ening, the 0.125 and $0.199 \mu \mathrm{m}$ peaks stand out in both distributions. Evident in the EC-produced distribution, at 0.19 and at $0.31 \mu \mathrm{m}$, are the charge doublet particles described in Sect. 2.2. When atomizing the $0.491 \mu \mathrm{m}$ hydrosol, we see that the PG-100 produces particles both larger and smaller than the PSL diameter. Presumably, the latter originate as a solution droplet devoid of a PSL sphere (Kinney et al., 1991).

The bottom and top panels of Fig. 5 demonstrate that the PG-100 produces particles at a diameter comparable to the minimum size detectable by the PCASP $(\sim 0.1 \mu \mathrm{m})$. Because of this, a parallel measurement of particle concentration, provided by a CPC, cannot, in general, be used as a reference for establishing the PCASP's aerosol flow calibration. The method we used for that flow calibration is described in Sect. 3.2.

\subsection{Particle shape}

The basis for this section is the concept of the sphereequivalent particle diameter. This is defined as the diameter of a virtual sphere with volume equal to that of an actual non-spherical particle. Laboratory investigations of light scattering by cubical particles (Perry et al., 1978; Liu et al., 1992), investigated over the angular scattering range detected by the PCASP $\left(35\right.$ to $120^{\circ}$ ), and for the laser wavelength of the PCASP $(\lambda=0.633 \mu \mathrm{m})$, demonstrated that a smaller scattering intensity is produced by a cubical particle relative to the sphere-equivalent particle. Measured and calculated scattering phase functions, presented by Perry et al. (1978), reveal opposing effects, depending on scattering angle. Larger forward scattering is produced by the sphere, and vice versa for backward scattering angles. Collins et al. (2000) also investigated PCASP detection of non-spherical particles. Using scattering phase functions reported by Mishchenko et al. (1997), Collins et al. (2000) concluded that the sizing difference, for a non-spherical versus a sphere-equivalent particle, would be $5 \%$ with the non-spherical sizing smaller than the spherical.

Other than interest in the basic nature of light scattering, there are two motivations for the investigations summarized in the previous paragraph. The first is the difficulty of deriving size-integrated properties (e.g., particulate mass concentration and radiant extinction), for dispersions of nonspherical particles, and the second is the concern that sizeintegrated properties, based on the sphere assumption, can be biased. In this section we investigate properties of two nonspherical particles: the PSL double and triple aggregates. Our analysis is based on sizing measurements from the PCASP-1 (optical diameter) and the SMPS (mobility diameter). These two diameters were evaluated as the mode of a time-averaged size distribution (averaging time $=300 \mathrm{~s}$ ). The test particles were detected subsequent to the aggregate preparation steps described in Sect. 2.3.

We complement our analysis with a calculated sphereequivalent diameter and a calculated mobility diameter. The 
Table 3. Mobility and optical diameters of PSL spheres and aggregates.

\begin{tabular}{clcccc}
\hline $\begin{array}{c}\text { PSL } \\
\text { diameter, } \mu \mathrm{m}\end{array}$ & $\begin{array}{l}\text { Number of PSL } \\
\text { sphere(s) in aggregate }\end{array}$ & $\begin{array}{c}\text { SMPS mode } \\
\text { diameter, } \mu \mathrm{m}\end{array}$ & $\begin{array}{c}\text { aCalculated mobility } \\
\text { diameter, } \mu \mathrm{m}\end{array}$ & $\begin{array}{c}\text { PCASP mode } \\
\text { diameter, } \mu \mathrm{m}\end{array}$ & $\begin{array}{c}{ }^{\mathrm{b} C a l c u l a t e d ~ s p h e r e-~} \\
\text { equivalent diameter, } \mu \mathrm{m}\end{array}$ \\
\hline 0.125 & 1 (single) & 0.13 & 0.12 & 0.12 & 0.12 \\
& 2 (double) & 0.17 & 0.17 & 0.15 & 0.16 \\
\hline 0.199 & 3 (triple) & 0.20 & 0.19 & 0.18 & 0.18 \\
& 1 (single) & 0.20 & 0.20 & 0.20 & 0.20 \\
& 2 (double) & 0.27 & 0.27 & 0.26 & 0.25 \\
\hline
\end{tabular}

\footnotetext{
a Derived using the formulation presented by Gysel et al. (2002, their Eq. 7), a dynamic shape factor $(\chi=1.13)$ adopted for both the double and triple aggregate (Hinds, 1999; their Table 3.2; Baron and Willeke, 2001; their Table 4.3), and a Cuningham slip correction factor (Eq. 8.34 in Seinfeld and Pandis (1998)). Because the shape factor for a linear triple aggregate is 1.27 (Baron and Willeke, 2001; their Table 4.3), and because there is good agreement between values in columns \#3 and \#4, it seems that the triple aggregates were arranged in a compact configuration. See text for details. ${ }^{\mathrm{b}}$ Derived as $\left(\# \times D_{\mathrm{PSL}}^{3}\right)^{1 / 3}$ where \# is the number of PSL spheres composing the aggregate.
}

latter was prescribed by a transition-regime dynamic shape factor $(\chi)$ (Hinds, 1999; their Table 3.2; Baron and Willeke, 2001; their Table 4.3), by a formulation developed by Gysel et al. (2002; their Eq. 7), and by a formulation of the Cunningham correction factor (Seinfeld and Pandis, 1998; their Eq. 8.34).

The calculated and measured diameters are presented in Table 3. Several features of this presentation require explanation. We note that the PSL size (column \#1) is presented with three-digit precision, and that the derived diameters (measured and calculated) are presented with two-digit precision. Rationale for this distinction is provided in Sect. 2.2. The fourth column has calculated mobility diameters based on the assumption that the shape factor is the same for both the double and triple aggregate $(\chi=1.13)$. In fact, the recommended shape factor is smaller for the double aggregate $(\chi=1.10)$ and larger for the triple aggregate $(\chi=1.15)$; in the latter case the value of $\chi$ depends on how the spheres are combined into the aggregate (Baron and Willeke, 2001; Table 4.3). Because we get better agreement between the measurement and calculation using $\chi=1.13$, a value nearly equal to that for the compact structure, we conclude that our triple aggregates were compact. Microscopy was not conducted to verify this inference. When we performed the calculation using a shape factor recommended for the linear triple aggregate structure $(\chi=1.27$; Baron and Willeke, 2001) we derived a calculated mobility diameter $8 \%$ larger than that in Table 3 . Given the SMPS's size resolution (Sect. 2.2), it seems that the linear and compact forms could be distinguished using that instrument. Further work is needed to substantiate this conclusion.

Paired results for the SMPS (measured and calculated), and for the PCASP (measured and calculated), are presented in the \#3/\#4 columns and in the \#5/\#6 columns of Table 3. The largest difference is $0.01 \mu \mathrm{m}$. As a relative difference, this is no larger than $7 \%$, and thus reasonably consistent with the resolution-limited uncertainties discussed in Sect. 2.2. Finally, we note that the $8 \%$ to $13 \%$ difference between the SMPS and the PCASP, for the aggregates, is consistent with a shape-dependent increase of the particle's transition regime drag force and the proportionate increase of their mobility diameter.

\section{Summary and conclusion}

We have described a set of calibration procedures for PCASPs operated on the Wyoming King Air. Essential parts of the calibration system - the electrostatic classifier, SMPS and plumbing infrastructure - are not portable, and so the calibrations were conducted in our laboratory between projects. Project-to-project shifts of the flowrate calibration are generally smaller than $10 \%$. Our approach to the size calibration is somewhat different from that previously reported (e.g., Liu et al., 1992). We associate the midpoint of the channel with the largest number of particle counts to the nominal PSL diameter. As is the case with the flow calibration, shifts in the size calibration have occurred through time (Table 1). These may have been the result of shifts in the optical system, or in the laser, and in either case these shifts may have been enhanced by the discrete nature of the PCASP's classification of particle size.

The methods we report had their beginnings in lab investigations conducted between 2001 and 2005. That preliminary work benefited from our fortunate access to a variety of aerosol preparation and measurement technologies. What evolved is a redundant set of measurements for sizing, size distribution and aerosol flowrate. Redundancy is evident in the three aspects of our analysis. For the size calibration we use monodisperse PSL particles, we classify them as aerosol, in an electrostatic classifier, and quantify the mode size using an SMPS operated in parallel with the tested PCASP. That approach was extended to our investigation of PCASP sizing of aggregates of PSL spheres. Also, in our analysis of the effect of the PCASP baseline voltage setting, the SMPS was used as a redundant metric of the size distribution. That analysis was aided by our inference that an important source 
Table A1. PCASP and CPC concentration statistics corresponding to Fig. 2.

\begin{tabular}{ccccccc}
\hline \multicolumn{4}{c}{ PCASP $\left(\mathrm{cm}^{-3}\right)$} \\
\hline $\begin{array}{c}\text { PSL } \\
\text { size }(\mathrm{nm})\end{array}$ & $\begin{array}{c}\text { Average } \\
\text { concentration, } \bar{n}\end{array}$ & $\begin{array}{c}\text { Standard } \\
\text { deviation, } \sigma\end{array}$ & $\begin{array}{c}\text { Poisson } \\
\text { error, } \sigma_{\mathrm{p}}\end{array}$ & $\begin{array}{c}\text { Average } \\
\text { concentration, } \bar{n}\end{array}$ & $\begin{array}{c}\text { Standard } \\
\text { deviation, } \sigma\end{array}$ & $\begin{array}{c}\text { Poisson } \\
\text { error, } \sigma_{\mathrm{p}}\end{array}$ \\
\hline 125 & 449 & 22 & 22 & 462 & 5 & 5 \\
152 & 333 & 19 & 19 & 336 & 4 & 4 \\
199 & 280 & 17 & 17 & 280 & 4 & 4 \\
491 & 45 & 7 & 7 & 43 & 2 & 2 \\
\hline
\end{tabular}

of variability in the compared size distributions is Poisson counting error. Finally, for the aerosol flowrate calibration, we used a bubble meter, and verified our determination of the flow calibration by comparing concentrations reported by the PCASP and a CPC.

\section{Appendix A}

Here we derive the Poisson counting error associated with a determination of particle concentration. Also, the analysis is extended to Poisson counting error in a determination of the particle size distribution function.

Considered here are two standard deviations. The first is the variability associated with an average concentration. The second is the Poisson counting error. The first is evaluated as

$\sigma=\sqrt{\frac{\sum\left(\bar{n}-n_{j}\right)^{2}}{N_{\#}-1}}$

where $N_{\#}$ is the number of measurements within an analyzed time series, $\bar{n}$ is the average concentration and $n_{j}$ is the concentration corresponding to the " $j$-th" sample.

Four test aerosols were evaluated. The PCASP-1 and CPC concentration time series are presented in Fig. 2. We see (Fig. 2a) that concentration was steady during intervals centered at 1400, 3800, 6100 and $8000 \mathrm{~s}$. The duration of these intervals is $700 \mathrm{~s}$. Values of $\bar{n}$ and $\sigma$, derived for these intervals, are presented in Table A1. Using averages presented in Table A1, a particle count can be estimated as

$N=t_{\mathrm{s}} \cdot \dot{V} \cdot \bar{n}$,

where $t_{\mathrm{S}}$ is the sample time ( $1 \mathrm{~s}$ for our data system performing $1 \mathrm{~Hz}$ sampling (Sect. 2.1)) and $\dot{V}$ is the aerosol flowrate. Using Eq. (A2), we evaluated a count for the PCASP$1\left(\dot{V}=0.97 \mathrm{~cm}^{3} \mathrm{~s}^{-1}\right)$ and for the CPC $\left(\dot{V}=17 \mathrm{~cm}^{3} \mathrm{~s}^{-1}\right)$. Assuming the count is Poisson distributed (Young, 1962, pp. 57-64), the Poisson error for particle concentration is

$\sigma_{\mathrm{p}}=\frac{\sqrt{N}}{t_{\mathrm{s}} \cdot \dot{V}}=\sqrt{\frac{\bar{n}}{t_{\mathrm{s}} \cdot \dot{V}}}$.
Poisson errors are reported in Table A1. Agreement between $\sigma$ (Eq. A1) and $\sigma_{\mathrm{p}}$ (Eq. A3) is excellent for both instruments. We note that the error is smaller for the CPC because it samples aerosol at a significantly larger volumetric rate. This result is consistent with Eq. (A3) but is not obvious from Eq. (A1). Further, we note that the absence of any indication of $\sigma>\sigma_{\mathrm{p}}$ establishes that the generator was steadily producing particles during the analyzed $700 \mathrm{~s}$ intervals. Both observations lead to the conclusion that the documented concentration variability (Table A1) is attributable to the samplevolume-dependent error described by Eq. (A3).

Analogous to Eq. (A3), but for the PCASP, the Poisson error associated with a logarithmic size distribution function can be formulated as

$$
\left(\frac{\sigma_{\mathrm{p}}}{\Delta \log _{10} D}\right)_{i}=\frac{1}{\left(\Delta \log _{10} D\right)_{i}} \cdot \sqrt{\frac{\bar{n}_{i}}{t_{\mathrm{s}} \cdot \dot{V}}},
$$

where $\bar{n}_{i}$ and $\left(\Delta \log _{10} D\right)_{i}$ are the average concentration and the logarithmic width of the " $i$-th" PCASP channel, and $t_{\mathrm{s}}$ is the sample time ( $1 \mathrm{~s}$ for our data system sampling at $1 \mathrm{~Hz}$ ). Equation (A4) describes the error estimate we overlay on the PCASP's logarithmic size distribution in Fig. 4.

For the SMPS size distribution the derivation of the Poisson error is complicated by an analysis step which translates a measured particle mobility distribution to a calculated logarithmic size distribution. For the " $i$-th" SMPS channel we evaluate the measured particle count as

$N_{i, \mathrm{M}}=t_{\mathrm{S}} \cdot \dot{V} \cdot T_{\mathrm{e}} \cdot f \cdot n_{i, \mathrm{C}}$.

Here $t_{\mathrm{S}}$ is the sample time (2.6 $\mathrm{s}$ for each SMPS channel), $\dot{V}$ is the SMPS aerosol flowrate $\left(5 \mathrm{~cm}^{3} \mathrm{~s}^{-1}\right), T_{\mathrm{e}}$ is the integral sampling efficiency $\left(T_{\mathrm{e}}=0.5\right.$; Kousaka et al., 1985), $f$ is the fraction of particles with +1 charge (TSI, 2000a) and $n_{i, \mathrm{C}}$ is the calculated concentration. The latter can be exported from the SMPS program (TSI, 2001). Analogous to Eq. (A4), but for a particle spectrometer like the SMPS, the Poisson error for the measured particle concentration can be evaluated as

$\frac{\sqrt{N_{i, \mathrm{M}}}}{t_{\mathrm{S}} \cdot \dot{V}}=\sqrt{\frac{T_{\mathrm{e}} \cdot f \cdot n_{i, \mathrm{C}}}{t_{s} \cdot \dot{V}}}$. 
With Eqs. (A5) and (A6), the relative Poisson error for the measured particle concentration is

$\frac{\sqrt{N_{i, \mathrm{M}}}}{N_{i, \mathrm{M}}}=\sqrt{\frac{1}{t_{\mathrm{S}} \cdot \dot{V} \cdot T_{\mathrm{e}} \cdot f \cdot n_{i, \mathrm{C}}}}$.

Going further, we assume that the relative Poisson error for the measured and calculated concentrations are proportional. With that assumption we derive an equation analogous to Eq. (A4), but for the SMPS.

$$
\left(\frac{\sigma_{\mathrm{p}}}{\Delta \log _{10} D}\right)_{i}=\frac{1}{\left(\Delta \log _{10} D\right)_{i}} \cdot \sqrt{\frac{n_{i, \mathrm{C}}}{t_{\mathrm{s}} \cdot \dot{V} \cdot T_{\mathrm{e}} \cdot f}}
$$

Equation (A8) describes the error estimate we overlay on the SMPS's logarithmic size distribution in Fig. 4.

Acknowledgements. Y. Cai's, J. Snider's and P. Wechsler's involvement in this project was supported by the Department of Atmospheric Science, NSF Award AGS-1034858 and NSF Award ATM-0745986, respectively. We acknowledge Matt Burkhart who designed, developed and maintained the data acquisition system.

Edited by: M. Wendisch

\section{References}

Baron, P. A. and Willeke, K.: Aerosol measurement: Principles, Techniques, and Applications, 2nd Edn., John Wiley and Sons, Inc., 1131 pp., New York, 2001.

Charlson, R. J., Schwartz, S. E., Hales, J. M., Cess, R. D., Coakley, J. A., Hansen Jr., J. E., and Hofmann, D. J.: Climate Forcing by anthropogenic Aerosols, Science, 255, 423-430, 1992.

Collins, D. R., Jonsson, H. H., Seinfeld, J. H., Flagan, R. C., Gassó, S., Hegg, D. A., Russell, P. B., Schmid, B., Livingston, J. M., Öström, E., Noone, K. J., Russell, L. M., and Putaud, J. P.: In situ aerosol-size distributions and clear-column radiative closure during ACE-2, Tellus, 52B, 498-525, 2000.

Covert, D., Wiedensohler, F., and Russell, L.: Particle charging and transmission efficiencies of aerosol charge neutralizers, Aerosol Sci. Technol., 27, 206-214, 1997.

Gysel, M., Weingartner, E., and Baltensperger, U.: Hygrospcopicity of aerosol particles at low temperatures. 2. Theoretical and experimental hygroscopic properties of laboratory generated aerosols, Environ. Sci. Technol., 36, 63-68, 2002.

Hinds, W. C.: Aerosol Technology: Properties, Behavior and Measurement of Airborne Particles, John Wiley and Sons, Inc., 483 pp., New York, 1999.

Kinney, P. D., Pui, D. Y. H., Mulholland, G. W., and Bryer, N. P.: Use of the electrostatic classification method to size 0.1 um SRM particles - A feasibility study, J. Res. Natl. Inst. Stan., 96, 147176, 1991.

Kleinman, L. I., Daum, P. H., Lee, Y. N., Senum, G. I., Springston, S. R., Wang, J., Berkowitz, C., Hubbe, J., Zaveri, R. A., Brechtel, F. J., Jayne, J., Onasch, T. B., and Worsnop, D.: Aircraft observations of aerosol composition and aging in New England and Mid-Atlantic States during the summer 2002 New England Air Quality Study field campaign, J. Geophys. Res., 112, D09310, doi:10.1029/2006JD007786, 2007.
Kleinman, L. I., Daum, P. H., Lee, Y. N., Lewis, E. R., Sedlacek, A. J., III, Senum, G. I., Springston, S. R., Wang, J., Hubbe, J., Jayne, J., Min, Q., Yum, S. S., and Allen, G.: Aerosol concentration and size distribution measured below, in, and above cloud from the DOE G-1 during VOCALS-REx, Atmos. Chem. Phys., 12, $207-$ 223, doi:10.5194/acp-12-207-2012, 2012.

Kousaka, Y., Okuyama, K., and Adachi, M.: Determination of particle size distribution of ultra-fine aerosol using a differential mobility analyzer, Aerosol Sci. Technol., 4, 209-225, 1985.

Liu, P. S. K., Leaitch, W. R., Strapp, J. W., and Wasey, M. A.: Response of Particle Measuring Systems airborne ASASP and PCASP to $\mathrm{NaCl}$ and latex particles, Aerosol Sci. Technol., 16, 83-95, 1992.

Mishchenko, M. I., Travis, L. D., Kahn, R. A., and West, R. A.: Modeling phase functions for dustlike tropospheric aerosols using a shape mixture of randomly oriented polydisperse spheroids, J. Geophys. Res., 102, 16831-16847, 1997.

Particle Measuring Systems, Particle Generator Model PG-100, Operator's Manual, PMS Inc., Boulder, Colorado, 1992.

Particle Measuring Systems, Passive Cavity Aerosol Spectrometer Probe (Airborne), PMS Model PCASP-100X 0.10-3.0 $\mu \mathrm{m}$, Operating Manual, PMS Inc., Boulder, Colorado, 2002.

Perry, R. J., Hunt, A. J., and Huffman, D.R.: Experimental determinations of Mueller scattering matrices for nonspherical particles, Appl. Optics, 17, 2700-2706, 1978.

Rosenberg, P. D., Dean, A. R., Williams, P. I., Dorsey, J. R., Minikin, A., Pickering, M. A., and Petzold, A.: Particle sizing calibration with refractive index correction for light scattering optical particle counters and impacts upon PCASP and CDP data collected during the Fennec campaign, Atmos. Meas. Tech., 5, 1147-1163, doi:10.5194/amt-5-1147-2012, 2012.

Seinfeld, J. H. and Pandis, S. N.: Atmospheric Chemistry and Physics, John Wiley and Sons, 1326 pp., New York, 1998.

Snider, J. R., Leon, D., and Wang, Z.: Droplet concentration in marine stratocumulus clouds: Part I, Atmos. Chem. Phys. Discuss., in preparation, 2013.

Strapp, J. W., Leaitch, W. R., and Liu, P. S. K.: Hydrated and dried aerosol-size-distribution measurements from the Particle Measuring Systems FSSP-300 probe and the deiced PCASP-100X probe, J. Atmos. Ocean. Tech., 9, 548-555, 1992.

Twomey, S.: Atmospheric Aerosols, Elsevier Scientific Publishing Company, Amsterdam, 302 pp., 1977.

TSI: Model 3080 Electrostatic Classifier Instruction Manual, St. Paul, Minnesota, 2000a.

TSI: Model 3075/3076 Constant Output Atomizer Instruction Manual, St. Paul, Minnesota, 2000b.

TSI: Model 3010 Condensation Particle Counter Instruction Manual, St. Paul, Minnesota, 2000c.

TSI: Aerosol Instrument Manager Software Instruction Manual, St. Paul, Minnesota, 2001.

Wang, Z., French, J., Vali, G., Wechsler, P., Haimov, S., Rodi, A., Deng, M., Leon, D., Snider, J. R., Peng, L. R., and Pazmany, A. L.: Single aircraft integration of remote sensing and in situ sampling for the study of cloud microphysics and dynamics, B. Am. Meteorol. Soc., 93, 653-668, doi:10.1175/BAMS-D-1100044.1, 2012.

Young, H. D.: Statistical Treatment of Experimental Data, McGrawHill Book Company, 172 pp., 1962. 